Alfarama Journal of Basic \& Applied Sciences

Faculty of Science Port Said University https://ajbas.journals.ekb.eg

ajbas@sci.psu.edu.eg

http://sci.psu.edu.eg/en/

January 2021, Volume 2, Issue 1

DOI: $10.21608 /$ ajbas.2020.44098.1036

Submitted: 02-10-2020

Accepted: 09-11-2020

Pages: 28-43

\title{
All-trans Retinoic Acid has Renoprotective Effects on Cisplatin-induced Acute Kidney Injury in Rats.
}

\begin{abstract}
Faten Zahran Mohamed ${ }^{1}$, Ibrahem Mohey Eldeen ${ }^{2}$, Nashwa Mohamed Barakat ${ }^{3}$, Mohsen Mohamed Mohamed Khedr ${ }^{4, *}$

${ }^{1}$ Department of Chemistry, Faculty of Science, Zagazig University, Zagazig, Egypt;

${ }^{2}$ Department of Chemistry, Faculty of Science, Port said university, Port said, Egypt.

${ }^{3}$ Urology and Nephrology center, Mansoura University, Mansoura, Egypt; (N.M.B.).

${ }^{4}$ Department of Chemistry, Faculty of Science, Port Said University, Port said, Egypt;
\end{abstract}

*Corresponding author: mohsenkhedr74@yahoo.com.

\begin{abstract}
All-trans retinoic acid (ATRA) is the active metabolites of vitamin A; it has antioxidant effects, and can regulate apoptosis. The present study aims to observe the effectiveness of ATRA on acute kidney injury induced by cisplatin, where a total of 96 Sprague-Dawley rats (180-220 g) were subdivided into four groups; (24 in each group); normal group, DMSO group, cisplatin group, and cisplatin with retinoic acid group. Eight rats were sacrificed on days 3, 7, and 11 in each group. Blood, urine and kidney tissue samples were collected for the determination of serum creatinine, blood urea nitrogen, MAU, and kidney tissue malondialdehyde (MDA), Catalase (CAT), glutathione reductase (GSH) levels, also for determination of the expression levels of nuclear factor- $\mathrm{kB}$ (NF- kB), Caspase-3, and TGF $\beta 1$, as well as histological examination.

Serum creatinine, BUN, MAU, and MDA levels were significantly increased, while the activities of CAT and GSH were significantly decreased as well as, the expression levels of caspase-3, NF-kB, and TGF $\beta 1$ were significantly increased in cisplatin group compared with those in normal and DMSO groups. In contrast, ATRA group showed lower levels of serum creatinine, BUN, MAU and MDA ( $p<0.05)$, and increased levels of CAT and GSH $(\mathrm{p}<0.05)$, which reached the highest levels at day 11, also the expression levels of caspase-3, NF-kB and TGF $\beta 1$ decreased significantly in ATRA group $(\mathrm{P}<0.05)$. In conclusion, ATRA has a protective effect on acute kidney injury induced by cisplatin in rats, and it plays an important role in decreasing of apoptosis, inflammation, and inhibition of lipid peroxidation.
\end{abstract}

Keywords:

All-trans retinoic acid, Cisplatin, AKI, lipid peroxidation, rats.

\section{1- INTRODUCTION}

Acute kidney injury (AKI) is a rapid decrease in renal function due to kidney damage, leading to the reservation of nitrogenous compounds (Urea and Creatinine) [1]. Many etiological factors can lead to AKI 
such as hypoxia, surgery, mechanical trauma, inflammation, hemodynamic instability and drugs such as chemo- and radiotherapy [2]. One of the most important chemotherapeutic drugs is cisplatin, since it is widely used for treatment of majority of solid tumors like lung, head and neck, breast, bladder, ovarian cancer, and cervical cancer [3].

Several studies confirmed a series of side effects on various organs resulted from the frequent use of cisplatin, the kidney is the major target organ that affected due to the accumulation of cisplatin at high concentrations in the kidney even at nontoxic plasma levels [4]. It has been evidenced that cisplatin induce nephrotoxicity by triggering apoptosis of proximal tubular cells which is followed by inflammation and fibrosis [5], another study reported that treatment with cisplatin cause degradation of anti-apoptotic proteins such as Bcl-2 and increase the levels of pro-apoptotic proteins, such as Bax that leads to induction of apoptosis [6].

Biotransformation of cisplatin into a highly reactive form within the kidney cells is an important mechanism of cisplatin-induced AKI, where cisplatin can interact and conjugate with glutathione (thiolcontaining antioxidant molecule) [7], leading to depletion of glutathione, that means suppression of antioxidant systems, which in turn results in the formation of reactive oxygen species (ROS) and accumulation of lipid peroxidation products in kidney [8], cisplatin also increased ROS through mitochondrial dysfunction and impairment of respiratory chain [9].

All-trans retinoic acid, is the active metabolite of vitamin A,and it has important roles in cell growth, differentiation, survival, reproduction [10], for instance it has an important role in the differentiation tubular cells, synthesis of collagen, fibronectin and laminin-I [11], one of the most important roles of ATRA, that, it can catch and act as scavenger of free radicals without interacting with biological targets, it also can undergo chain breaking effects that have antioxidant effects through preventing lipid peroxidation in the cell membrane [12], the present study was designed to investigate the effects of ATRA on cisplatin induced acute kidney injury in rats.

\section{MATERIALS AND METHODS:}

\subsection{Experimental Animals:}

A total number of 96 male Sprague-Dawley (SD) rats weighting approximately (180-220) g, were used in the experiment, all animals were obtained from Urology and Nephrology Center, Mansoura University, Mansoura, Egypt with certificate No. (code \# MDP.19.12.35.R1), all animals were housed under standard conditions at $20{ }^{\circ} \mathrm{C}$ with 12 -h light/12-h dark cycle, and received humane care during the study and were fed a standard diet with free access to chow and water ad libitum.

\subsection{Preparation of all -trans retinoic acid (ATRA) (Sigma Aldrich, USA):}

ATRA was prepared in Dimethylsulfoxide (DMSO) (the vehicle of all-trans retinoic acid), as a stock solution of concentration $(0.01 \mathrm{M})$, then it was filtered by using syringe filter $0.2 \mu \mathrm{m}$, and it was keept in a light protected vials at $-20^{\circ} \mathrm{C}$, until it was used, before use a $25 \mu 1$ from the stock solution was taken, diluted with tissue culture medium and filtered right again before use.

\subsection{Experimental design:}

The Four groups of animals used in the present study were (i) the control group $(n=24)$ received $1 \mathrm{ml}$ normal saline alone (I.P), (ii) DMSO group ( $\mathrm{n}=24)$, rats were given $1 \mathrm{ml}$ Dimethyl sulfoxide (I.P), (iii) Cisplatin group $(n=24)$, this group was subjected to cisplatin induced acute kidney injury, where rats were injected with a single dose of Cisplatin $(6 \mathrm{mg} / \mathrm{kg} \mathrm{bw}$ ) (I.P), (iiii) Cisplatin and ATRA group (ATRA treated group) $(\mathrm{n}=24)$ in which each rat was injected intraperitoneally with Cisplatin $(6 \mathrm{mg} / \mathrm{Kg}$ body weight), then, rats were injected intravenously (via the tail vein) with $10 \mu \mathrm{M}$ ATRA one day after Cisplatin injection. Before scarification of each group, urine samples have been collected randomly from metabolic cages for estimation of Microalbuminuria (MAU). Eight rats were sacrificed at different time intervals in all groups at days 3, 7 and 11, then blood and kidney tissue samples were obtained. 


\subsection{Biochemical Measurements:}

The levels of serum creatinine were estimated in accordance with the instructions of creatinine kit (Diamond diagnostics company, Jaffe, calorimetric - kinetic, Hannover, Germany), while the levels of Blood urea nitrogen (BUN) were determined according to the instructions of urea kit (Diamond diagnostics company, Berthelot enzymatic colorimetric method, Hannover, Germany). Microalbuminuria was determined according to [13], by using Albumin (Microalbuminuria) Kit (COD: 31924), these parameters was measured by a clinical chemistry Analyzer Architect c4000 system (Abbott Diagnostics, Wiesbaden, Germany), also the levels of CAT [14], GSH [15] and MDA [16] were assessed in kidney tissue by using a reagent kit provided by Biodiagnostic (Giza, Egypt).

\subsection{Real-time PCR for Caspase-3, NF-kB and TGF $\beta$ genes:}

By using Qiagen tissue extraction kit (Qiagen, USA), extraction of total RNA from kidney tissue homogenate was done, and analyzed depending on the method described by [17], where the RQ1 RNasefree DNase (promega, USA) was used to purify the extracted RNA and to get rid of contamination of DNA, and then, $1 \mu \mathrm{g}$ from a purified mRNA was reverse transcribed to synthesized cDNA by using high capacity cDNA reverse transcription kit (Applied Biosystem, USA). Quantitative RT-PCR reactions were carried out with SYBER Green PCR Master Mix kit (Applied Biosystem, USA) and were performed using an Applied Biosystem (Step One ${ }^{\mathrm{TM}}$, USA). The PCR reaction protocol was performed as follow: one cycle for 2 min at $50{ }^{\circ} \mathrm{C}$ for amplification, followed by 40 cycles each of them consisting of three steps denaturation step for $15 \mathrm{~s}$ at $95{ }^{\circ} \mathrm{C}$, annealing step for $1 \mathrm{~min}$ at $60{ }^{\circ} \mathrm{C}$, and elongation step for $1 \mathrm{~min}$ at $72{ }^{\circ} \mathrm{C}$. Gene expression levels were calculated using software step one real time PCR by using the following equation. Relative Quantification $(\mathrm{RQ})=2^{-\Delta \Delta \mathrm{CT}}$

Where, $\Delta \Delta \mathrm{CT}=(\mathrm{CT}$ target gene $-\mathrm{CT}$ GAPDH$)$ disease $-(\mathrm{CT}$ target gene $-\mathrm{CT}$ GAPDH $)$ control. The Selective primer sequences that were used were demonstrated in Table $\mathbf{1 .}$

\subsection{Histopathological examination:}

After scarification of animals, one kidney was removed by surgery and fixed in $10 \%$ buffered formalin, and prepared as described by routine Histopathological practices, where fragments of kidney tissue were dehydrated after fixation, cleaned and then embedded in paraffin, by using a microtome (Leica RM 2155 , England) kidney tissue were prepared ( $5 \mu \mathrm{m}$ thicknesses of the cortex and the medulla) and stained routinely with hematoxylin / eosin (H\&E) for illustration of the Histopathological studies by bright field light microscope (Olympus CX51 light microscope, Tokyo, Japan), Pictures were obtained by a PC-driven digital camera (Olympus E-620), computer software (Cell*, Olympus Soft Imaging Solution GmbH). The scoring system considered two main properties, the active injury changes that include (tubular necrosis, counted as the number of necrotic tubules/high power field (HPF): $1=1-3$ necrotic tubules/ HPF; $2=4-5$ necrotic tubules /HPF; $3=6-10$ necrotic tubules/HPF; and $4=>10$ necrotic tubules/HPF, and the number of rows of interstitial inflammatory cells that scored as $1=1-3$ rows in between the tubules; $2=4-5$ rows in between the tubules; and $3=$ or $>6$ rows in between the tubules.), while the second property is the regenerative changes that include the presence of mitosis and solid sheets between the tubules.

\subsection{Statistical Analysis:}

Results were expressed as mean \pm standard deviation and statistical differences were done by ANOVA one-way analysis of variance taken $\mathrm{p}<0.05$ as a confidence interval. The Histopathological parameters scores were reported as median. Differences in median were performed by Mann-whitney U test. All statistical analysis was performed using SPSS version 20 (IBM Corp., Armonk, NY, USA), and p $<0.05$ was considered to indicate a statistically significant difference. 
-Table (1). List of primer sequence:

\begin{tabular}{|l|l|l|c|}
\hline Target gene & \multicolumn{1}{|c|}{ Nucleotide sequence } & Gen Bank accession no. & Reference \\
\hline Caspase-3 & $\begin{array}{l}\text { F:5-GGACCTGTGGACCTGAAAAA-3 } \\
\text { R:5-GCATGCCATATCATCGTCAG-3 }\end{array}$ & NM_012922.2 & {$[18]$} \\
\hline NF-kB & $\begin{array}{l}\text { F:5-GGACAGCACCACCTACGATG-3 } \\
\text { R:5-CTGGATCACTTCAATGGCCTC-3 }\end{array}$ & NM_001276711.1 & {$[19]$} \\
\hline TGFß1 & $\begin{array}{l}\text { F:5-CTGCTGACCCCCACTGATAC-3 } \\
\text { R:5-AGCCCTGTATTCCGTCTCCT-3 }\end{array}$ & NM_021578.2 & {$[20]$} \\
\hline \multirow{2}{*}{ GAPDH } & $\begin{array}{l}\text { F:5-TATCGGACGCCTGGTTAC-3 } \\
\text { R:5-CTGTGCCGTTGAACTTGC-3 }\end{array}$ & NM_017008.4 & {$[21]$} \\
\hline
\end{tabular}

\section{RESULTS:}

\subsection{Effect of ATRA treatment in alleviating renal injury induced by cisplatin.}

The present results showed that there is no significant difference in the levels of serum creatinine, BUN and Microalbuminuria between control group and DMSO group. As expected the injection of cisplatin markedly increased serum creatinine (Fig. 1), BUN (Fig. 2) and Microalbuminuria (Fig. 3) that reached maximum on day 3 after cisplatin injection compared to control group at days 3, 7, and 11 ( $\mathrm{p}<0.05$ ). Interestingly, administration of ATRA significantly decreased serum creatinine, BUN and Microalbuminuria levels at 3, 7 and 11 days ( $<<0.05$ ), which confirmed the ability of ATRA to attenuate the renal injury induced by cisplatin with the most attenuation at day 11, Table 2.

\subsection{Effect of ATRA treatment on oxidative stress parameters.}

As mentioned in Table 3, there is no change in MDA content (Fig. 4), GSH (Fig. 5), and CAT (Fig. 6), activity between normal control group and DMSO group. By contrast, Cisplatin injection caused significantly increase in MDA content, and a significant reduction in the enzymatic activities of GSH and CAT compared with control group $(\mathrm{P}<0.05)$, with the maximum changes appeared on day 3 after cisplatin injection. Meanwhile, the administration of ATRA lead to improved oxidative stress parameters appeared in the significant reduction of MDA content and a significant increase in GSH and CAT enzymatic activity with maximal increments appeared on day $11(\mathrm{P}<0.05)$, these rsults suggest that ATRA has effective role in the decrement of oxidative damage, Table 3. 
Table (2): Effect of ATRA administration on serum kidney function parameters (creatinine, BUN, MAU).

\begin{tabular}{|c|c|c|c|c|}
\hline Parameter & Group & $3 \mathrm{D}$ & $7 \mathrm{D}$ & $11 \mathrm{D}$ \\
\hline \multirow{4}{*}{$\mathrm{S} \mathrm{Cr}(\mathrm{mg} / \mathrm{dl})$} & Control & $0.56 \pm 0.05$ & $0.56 \pm 0.06$ & $0.55 \pm 0.06$ \\
\hline & DMSO & $0.57 \pm 0.05$ & $0.56 \pm 0.05$ & $0.56 \pm 0.04$ \\
\hline & CIS & $5.26 \pm 0.74^{\mathrm{a}}$ & $3.55 \pm 0.43^{\mathrm{a}}$ & $1.83 \pm 0.61^{\mathrm{a}}$ \\
\hline & CIS+ ATRA & $3.11 \pm 0.60^{\mathrm{ab}}$ & $2.35 \pm 0.64^{\mathrm{ab}}$ & $1.44 \pm 0.44^{\mathrm{ab}}$ \\
\hline \multirow{4}{*}{ BUN (mg/dl) } & Control & $21.23 \pm 1.31$ & $22.16 \pm 0.72$ & $22.85 \pm 1.26$ \\
\hline & DMSO & $23.23 \pm 2.05$ & $23.83 \pm 1.68$ & $24.01 \pm 1.26$ \\
\hline & CIS & $80.50 \pm 3.44^{\mathrm{a}}$ & $53.5 \pm 5.44^{\mathrm{a}}$ & $38.16 \pm 3.81^{\mathrm{a}}$ \\
\hline & CIS + ATRA & $62.16 \pm 8.23^{\mathrm{ab}}$ & $42.33 \pm 5.50^{\mathrm{ab}}$ & $32.08 \pm 4.27^{\mathrm{ab}}$ \\
\hline \multirow{4}{*}{ MAU (mg/dl) } & Control & $1.02 \pm 0.11$ & $1.03 \pm 0.22$ & $0.96 \pm 0.15$ \\
\hline & DMSO & $1.04 \pm 0.16$ & $1.07 \pm 0.19$ & $1.00 \pm 0.12$ \\
\hline & CIS & $9.75 \pm 1.60^{\mathrm{a}}$ & $5.41 \pm 1.09^{\mathrm{a}}$ & $2.83 \pm 0.75^{\mathrm{a}}$ \\
\hline & CIS+ ATRA & $5.78 \pm 0.77^{\mathrm{ab}}$ & $4.13 \pm 0.55^{\mathrm{ab}}$ & $2.15 \pm 0.41^{\mathrm{ab}}$ \\
\hline
\end{tabular}

Significant difference $(\mathrm{p} \leq 0.05)$, vs ${ }^{\mathrm{a}} \mathrm{control}$ group and vs ${ }^{\mathrm{b}}$ cisplatin group by one-way analysis of variance (ANOVA) followed by posthoc multiple comparisons (Scheffé test).

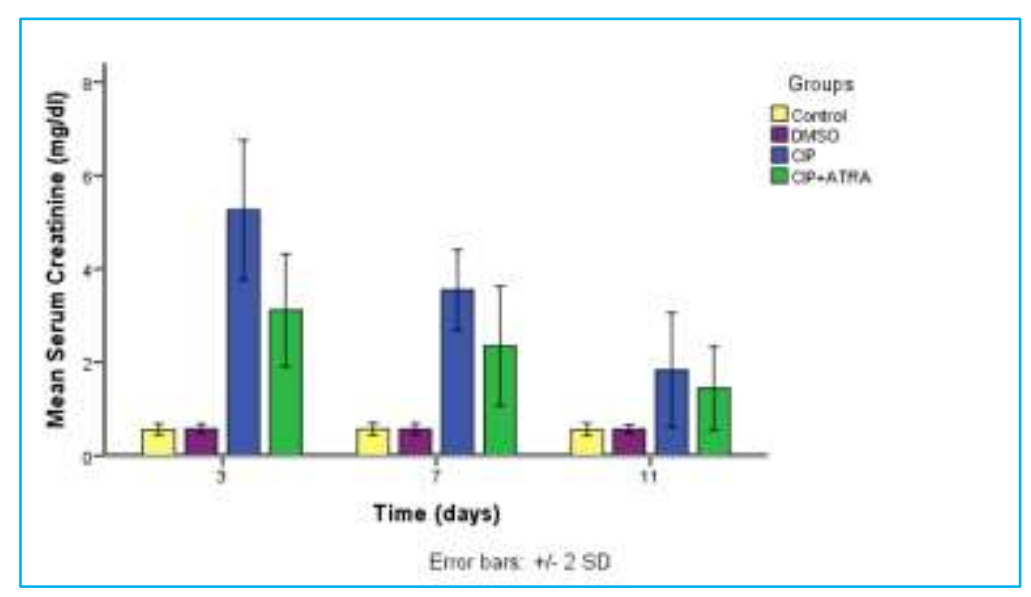

Fig. (1): Effect of Retinoic acid on Serum creatinine. 


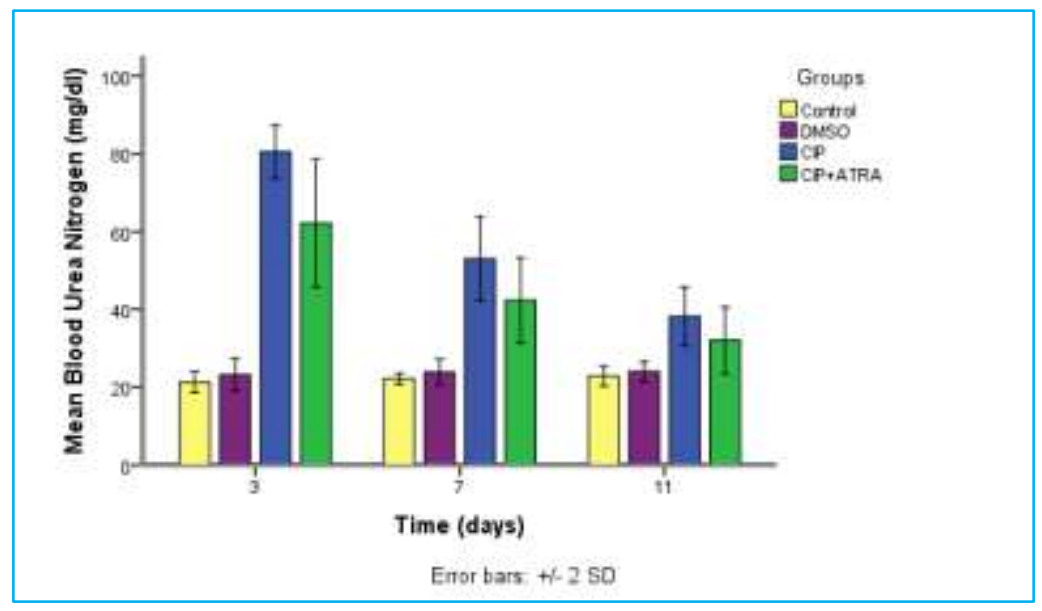

Fig. (2): Effect of Retinoic acid on BUN.

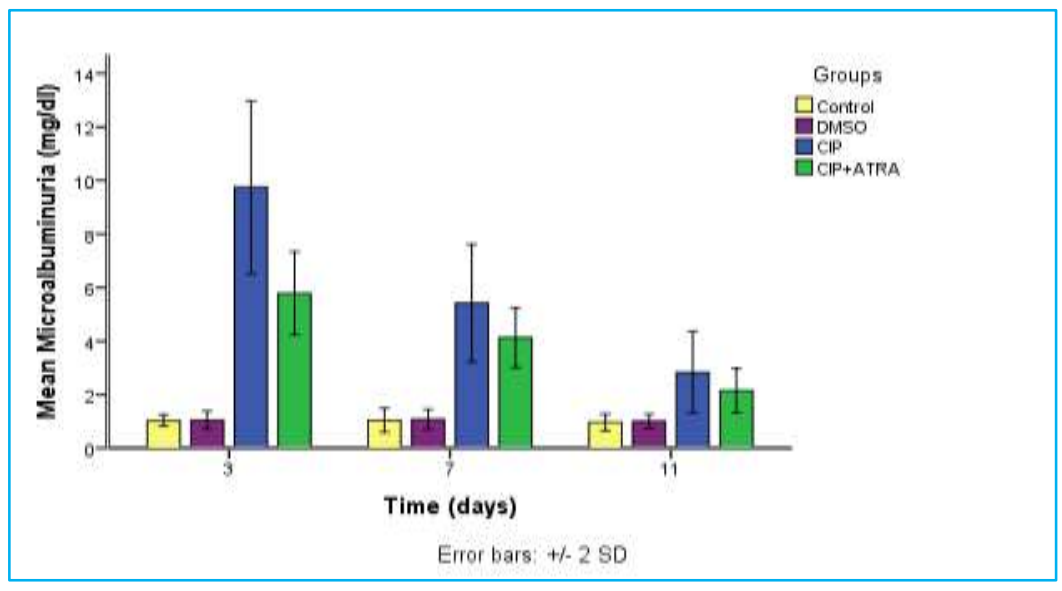

Fig. (3): Effect of Retinoic acid MAU.

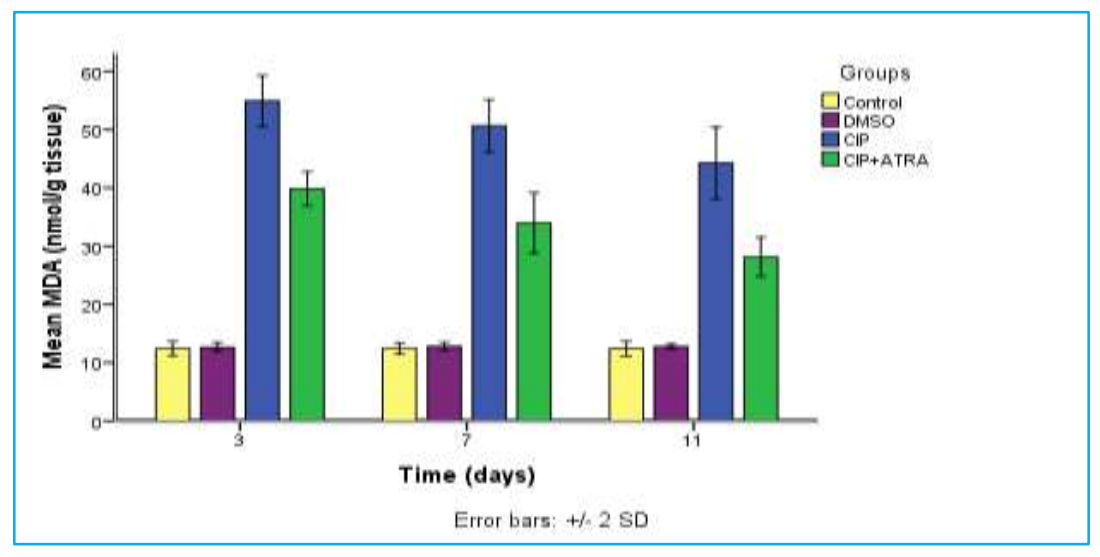

Fig. (4): Effect of Retinoic acid on MDA. 
-Table (3). Effect of ATRA administration on oxidative stress parameters (MDA, GSH, and CAT):

\begin{tabular}{|l|l|l|l|l|}
\hline \multirow{2}{*}{ Parameter } & Group & \multicolumn{1}{|c|}{$3 \mathrm{D}$} & \multicolumn{1}{c|}{$7 \mathrm{D}$} & \multicolumn{1}{c|}{$11 \mathrm{D}$} \\
\hline \multirow{4}{*}{ MDA(nmol/g tissue) } & Control & $12.4 \pm 0.5$ & $12.42 \pm 0.44$ & $12.39 \pm 0.6$ \\
\cline { 2 - 5 } & DMSO & $12.6 \pm 0.4$ & $12.76 \pm 0.35$ & $12.73 \pm 0.23$ \\
\cline { 2 - 5 } & CIS & $54 \pm 2.1^{\mathrm{a}}$ & $50 \pm 2.2^{\mathrm{a}}$ & $44.2 \pm 3.09^{\mathrm{a}}$ \\
\cline { 2 - 5 } & CIS+ ATRA & $39.8 \pm 1.4^{\mathrm{ab}}$ & $33.9 \pm 2.5^{\mathrm{ab}}$ & $28.1 \pm 1.6^{\mathrm{ab}}$ \\
\hline \multirow{5}{*}{ GSH (mg/g tissue) } & Control & $6.08 \pm 0.08$ & $6.1 \pm 0.11$ & $6.4 \pm 0.2$ \\
\cline { 2 - 5 } & DMSO & $5.9 \pm 0.19^{\mathrm{a}}$ & $5.92 \pm 0.17$ & $6.02 \pm 0.1$ \\
\cline { 2 - 5 } & CIS & $1.5 \pm 0.1^{\mathrm{a}}$ & $1.61 \pm 0.16^{\mathrm{a}}$ & $1.7 \pm 0.06^{\mathrm{a}}$ \\
\cline { 2 - 5 } & CIS+ ATRA & $2.1 \pm 0.15^{\mathrm{ab}}$ & $2.7 \pm 0.16^{\mathrm{ab}}$ & $2.9 \pm 0.15^{\mathrm{ab}}$ \\
\hline & Control & $5.16 \pm 0.2$ & $5.28 \pm 0.24$ & $5.31 \pm 0.2$ \\
\cline { 2 - 5 } & DMSO & $5.25 \pm 0.2$ & $5.31 \pm 0.33$ & $5.37 \pm 0.3$ \\
\cline { 2 - 5 } & CIS & $1.19 \pm 0.18^{\mathrm{a}}$ & $1.25 \pm 0.11^{\mathrm{a}}$ & $1.39 \pm 0.08^{\mathrm{a}}$ \\
\cline { 2 - 5 } & CIS+ ATRA & $2.15 \pm 0.1^{\mathrm{ab}}$ & $2.57 \pm 0.17^{\mathrm{ab}}$ & $2.8 \pm 0.15^{\mathrm{ab}}$ \\
\hline
\end{tabular}

Significant difference $(\mathrm{p} \leq 0.05)$, vs ${ }^{\mathrm{a}}$ control group and vs ${ }^{\mathrm{b}}$ cisplatin group by one-way analysis of variance (ANOVA) followed by posthoc multiple comparisons (Scheffé test).

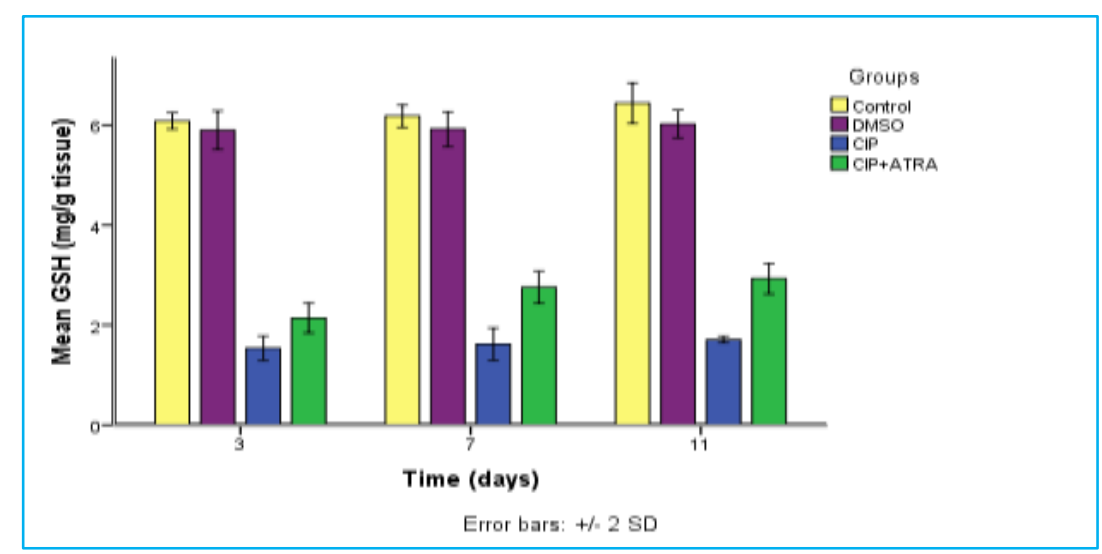

Fig. (5): Effect of Retinoic acid on GSH.

\subsection{Effect of ATRA on gene expression of $\mathrm{NF}_{\mathrm{KB}}$, TGF $\beta 1$ and Caspase- 3 in kidney tissues:}

With respect to gene expression, the inflammatory markers $\mathrm{NF}_{\mathrm{KB}}$ (Fig. 7), TGF $\beta 1$ (Fig. 8) and apoptotic marker Caspase-3 (Fig. 9) were significantly increased in Cisplatin group compared to control group at the three time intervals $(\mathrm{P}<0.05)$, with the highest increase on day 3. Meanwhile the administration of ATRA significantly down regulated the expression of those genes as compared with cisplatin group, with the maximal regulation on day $11(\mathrm{P}<0.05)$, Table 4. 


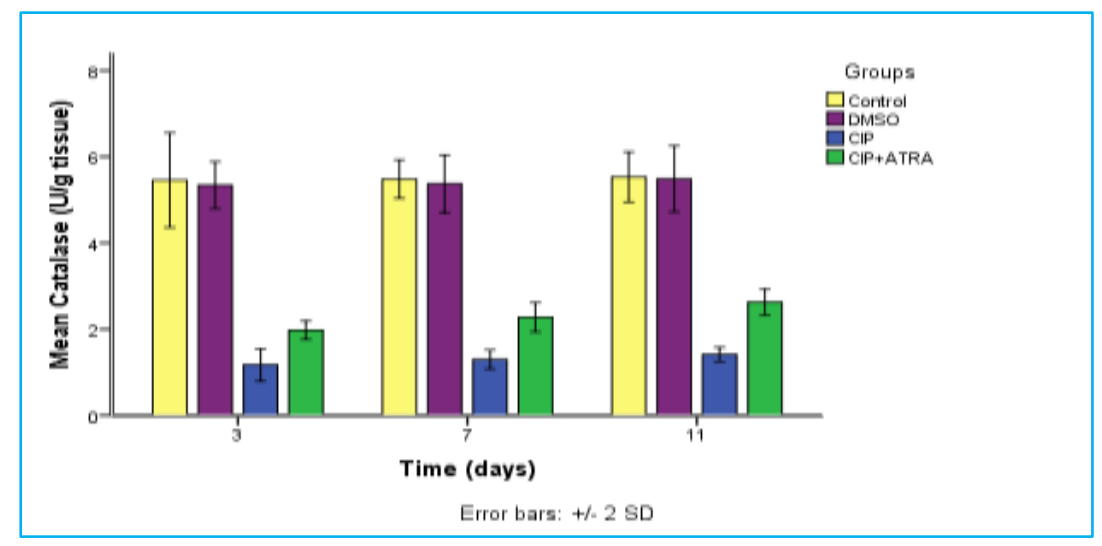

Fig. (6): Effect of Retinoic acid on CAT activity.

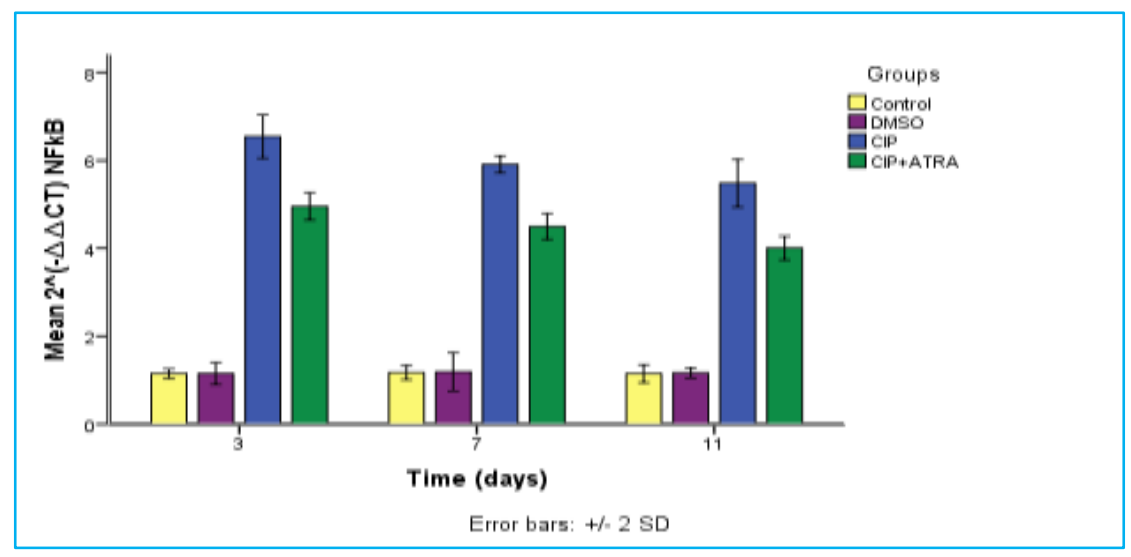

Fig. (7): Effect of Retinoic acid on $\mathrm{NF}_{\mathrm{KB}}$ expression in kidney.

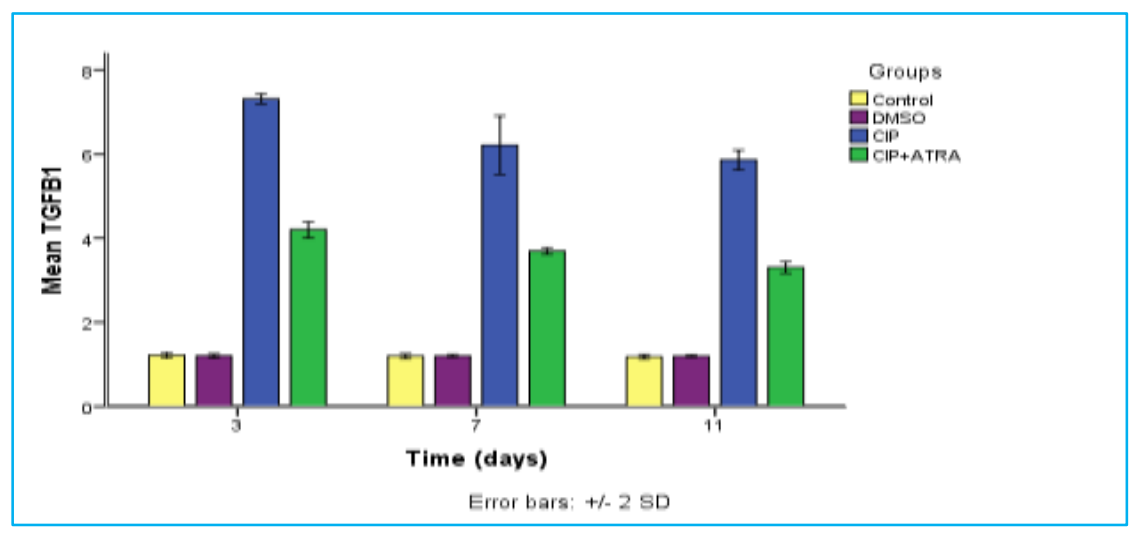

Fig. (8): Effect of Retinoic acid on TGF $\beta 1$ expression in kidney. 


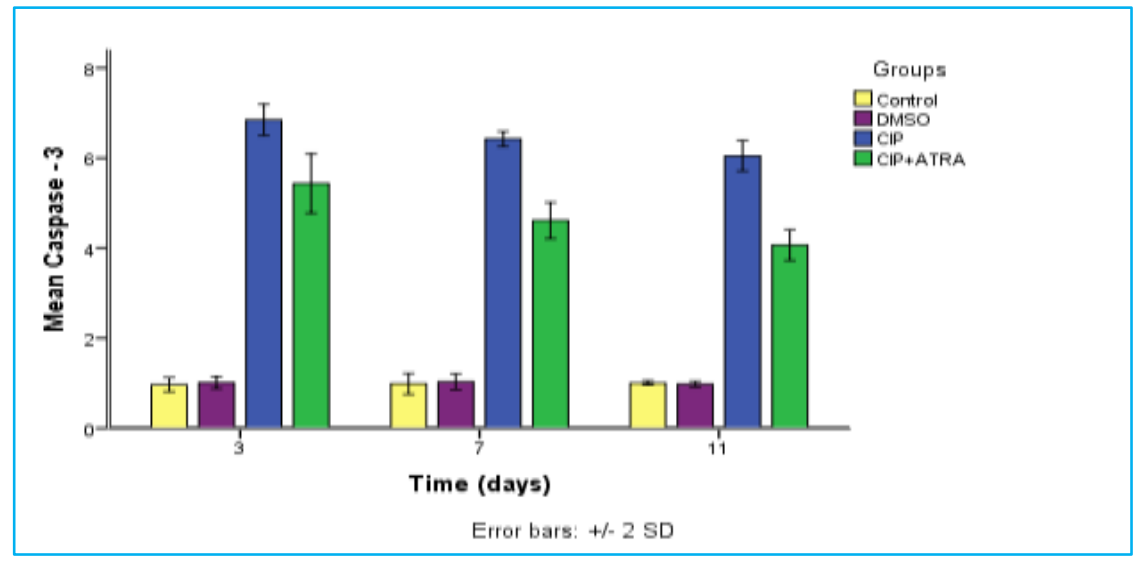

Fig. (9): Effect of Retinoic acid on caspase-3 expression in kidney.

-Table (4). Effect of ADMSCs on the expression level of $\mathrm{NF}_{\mathrm{KB}}$, TGF $\beta 1$ and Caspase-3 genes.

\begin{tabular}{|c|c|c|c|c|}
\hline Parameter & Group & $3 \mathrm{D}$ & $7 \mathrm{D}$ & $11 \mathrm{D}$ \\
\hline \multirow{4}{*}{$\mathbf{N F}_{\mathbf{K B}}$} & Control & $1.11 \pm 0.06$ & $1.14 \pm 0.09$ & $1.12 \pm 0.14$ \\
\hline & DMSO & $1.13 \pm 0.13$ & $1.15 \pm 0.1$ & $1.14 \pm 0.07$ \\
\hline & CIS & $6.2 \pm 0.24^{\mathrm{a}}$ & $5.7 \pm 0.09^{\mathrm{a}}$ & $5.23 \pm 0.27^{\mathrm{a}}$ \\
\hline & CIS + ATRA & $4.8 \pm 0.15^{\mathrm{ab}}$ & $4.5 \pm 0.14^{\mathrm{ab}}$ & $4.13 \pm 0.13^{\mathrm{ab}}$ \\
\hline \multirow{4}{*}{ TGFß1 } & Control & $1.23 \pm 0.05$ & $1.19 \pm 0.04$ & $1.18 \pm 0.04$ \\
\hline & DMSO & $1.25 \pm 0.05$ & $1.27 \pm 0.08$ & $1.19 \pm 0.09$ \\
\hline & CIS & $5.86 \pm 0.13^{\mathrm{a}}$ & $6.22 \pm 0.31^{\mathrm{a}}$ & $7.21 \pm 0.06^{\mathrm{a}}$ \\
\hline & $\mathrm{CIS}+\mathrm{ATRA}$ & $4.19 \pm 0.09^{\mathrm{ab}}$ & $3.59 \pm 0.04^{\mathrm{ab}}$ & $3.29 \pm 0.07^{\mathrm{ab}}$ \\
\hline \multirow{4}{*}{ Caspase-3 } & Control & $0.98 \pm 0.2$ & $0.99 \pm 0.11$ & $0.96 \pm 0.07$ \\
\hline & DMSO & $1.03 \pm 0.06$ & $1.05 \pm 0.08$ & $0.99 \pm 0.02$ \\
\hline & CIS & $6.06 \pm 0.17^{\mathrm{a}}$ & $6.51 \pm 0.06^{\mathrm{a}}$ & $6.75 \pm 0.17^{\mathrm{a}}$ \\
\hline & CIS + ATRA & $5.42 \pm 0.33^{\mathrm{ab}}$ & $4.63 \pm 0.22^{\mathrm{ab}}$ & $4.16 \pm 0.19^{\mathrm{ab}}$ \\
\hline
\end{tabular}

Significant difference $(\mathrm{p} \leq 0.05)$, vs ${ }^{\mathrm{a}}$ control group and vs ${ }^{\mathrm{b}}$ cisplatin group by one-way analysis of variance (ANOVA) followed by posthoc multiple comparisons (Scheffé test). 


\subsection{Histopathological Examination:}

Histopathological examination of kidney tissue of control group and DMSO group showed normal structure of the kidney as illustrated in Fig. 10 (A, B) respectively, which indicate that DMSO (the vehicle of all-trans retinoic acid) did not induce any pathological changes in the kidney histology. By contrast, injection of Cisplatin resulted in a statistically significant higher cortical and medullary damage score at 3, 7 and 11 days (p < 0.05), Fig. $10(\mathbf{C}, \mathbf{D}, \mathbf{E}, \mathbf{F}, \mathbf{G}, \mathbf{H})$ respectively, which appeared as apoptosis, dilated irregular tubules, loss of brush borders and casts formation and interstitial inflammatory infiltrate. Regarding ATRA group, Histopathological scores were decreased in both cortex region and medullary region, and the decrease in the degeneration score in medullary region was more statistically significant than that in the cortex region specially on day 11 as illustrated in Fig. 11 (A, B, C, D, E, F), at the same time, ATRA group showed statistically significant higher cortical and medullary regenerative indices (mitosis, solid tubules and sheets and prominent nucleoli) than control and cisplatin groups ( $\mathrm{p}$ value $<0.05$ ) in cortex and medulla region Fig. 11 (A, B, C, D, E, F), Table 5.

-Table (5): Histopathological changes of the Inner cortex and outer medulla in the rat kidney.

\begin{tabular}{|c|c|c|c|c|c|c|}
\hline \multirow{2}{*}{$\begin{array}{l}\text { Histological changes } \\
\text { Necrotic tubules score }\end{array}$} & \multicolumn{2}{|c|}{$3 \mathrm{D}$} & \multicolumn{2}{|c|}{$7 \mathrm{D}$} & \multicolumn{2}{|c|}{$11 \mathrm{D}$} \\
\hline & Cortex & Medulla & Cortex & Medulla & Cortex & Medulla \\
\hline Control & 0 & 0 & 0 & 0 & 0 & 0 \\
\hline DMSO & 0 & 0 & 0 & 0 & 0 & 0 \\
\hline CIS & $6^{\mathbf{a}}$ & $5^{a}$ & $6^{\mathbf{a}}$ & $3^{\mathbf{a}}$ & $6^{\mathbf{a}}$ & $2^{\mathbf{a}}$ \\
\hline $\mathrm{CIS}+\mathrm{RA}$ & $5^{\mathbf{a b}}$ & $4^{a}$ & $4^{a}$ & $2^{a}$ & $4^{a}$ & $1^{a}$ \\
\hline \multicolumn{7}{|l|}{$\begin{array}{l}\text { Interstitial infiltration } \\
\text { score }\end{array}$} \\
\hline Control & 0 & 0 & 0 & 0 & 0 & 0 \\
\hline DMSO & 0 & 0 & 0 & 0 & 0 & 0 \\
\hline CIS & $6^{\mathbf{a}}$ & $6^{\mathbf{a}}$ & $6^{a}$ & $6^{a}$ & $6^{\mathbf{a}}$ & $6^{\mathbf{a}}$ \\
\hline $\mathrm{CIS}+\mathrm{RA}$ & $6^{\mathbf{a b}}$ & $5^{a}$ & $5^{a}$ & $4^{a}$ & $5^{a}$ & $1^{\mathbf{a}}$ \\
\hline \multicolumn{7}{|l|}{ Regeneration score } \\
\hline Control & 0 & 0 & 0 & 0 & 0 & 0 \\
\hline DMSO & 0 & 0 & 0 & 0 & 0 & 0 \\
\hline CIS & $0^{\mathbf{a}}$ & $1^{\mathbf{a}}$ & $1^{\mathbf{a}}$ & $0^{\mathbf{a}}$ & $2^{a}$ & $1^{\mathbf{a}}$ \\
\hline $\mathrm{CIS}+\mathrm{RA}$ & $4^{\mathbf{a b}}$ & $5^{a b}$ & $6^{\mathbf{a b}}$ & $6^{\mathbf{a b}}$ & $6^{\mathbf{a b}}$ & $6^{\mathbf{a b}}$ \\
\hline
\end{tabular}

Significant difference compared to ${ }^{\mathrm{a}}$ control group and vs ${ }^{\mathrm{b}}$ cisplatin by Mann-whitney U test with $\mathrm{p}<0.05$. 

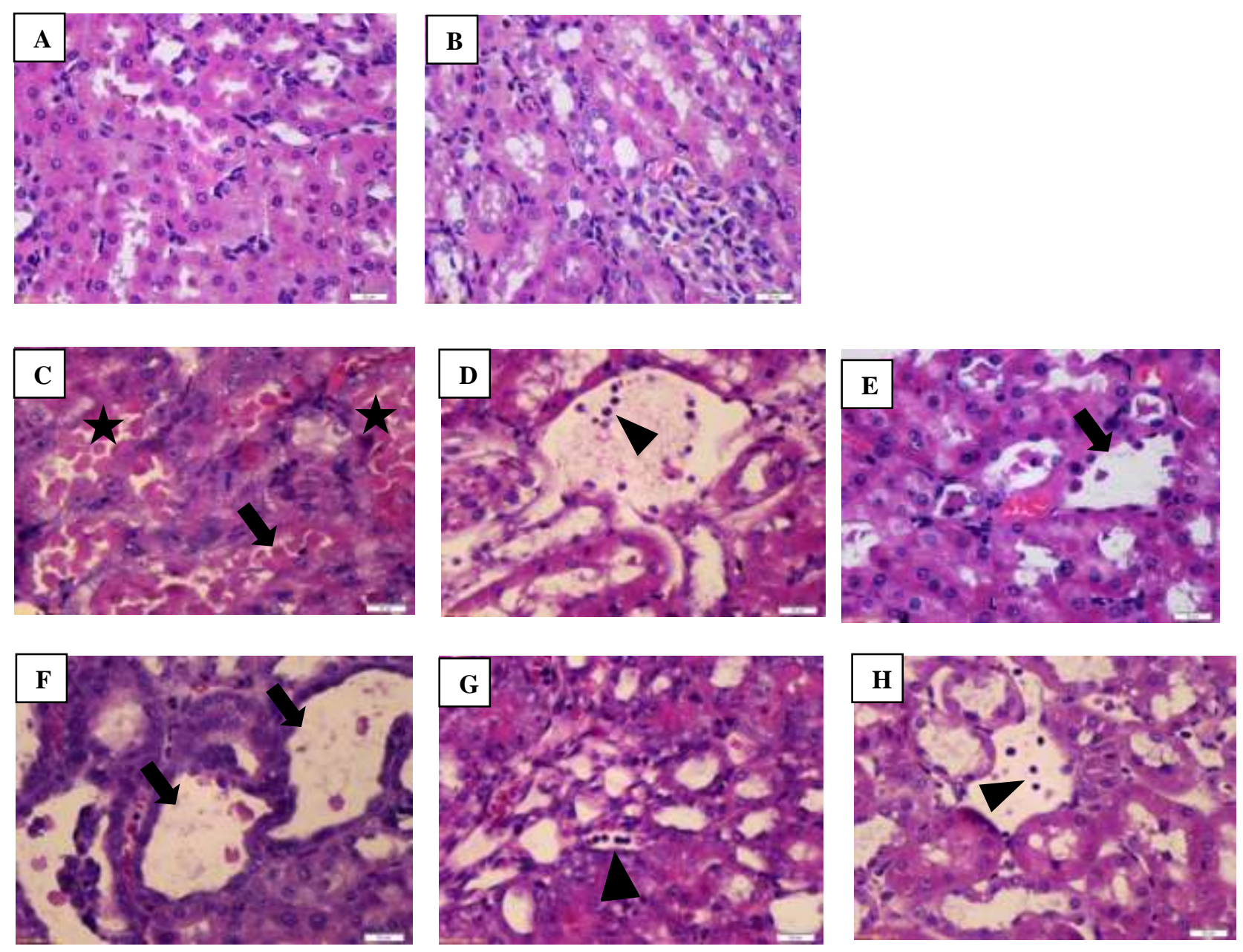

Fig (10): Histopathological analysis of the kidney stained with H\&E.
A) Control group shows normal kidney structure.
B) DMSO group shows normal kidney structure.

-Renal degenerative changes in cisplatin group show,

C) Apoptosis and tubular necrosis (Black arrow) in cortex with hyaline casts (Black star) at day 3 .

D) Mild interstitial inflammatory infiltrate (arrow head) in cortex at day 7 .

E) Mild apoptosis and tubular necrosis (Black arrow) in cortex with hyaline casts at day 11 .

F) Apoptosis dilated irregular tubules (Black arrow) in medulla at day 3.

G) Interstitial inflammatory infiltrate (arrow head) in medulla at day 7 .

H) Mild interstitial inflammatory infiltrate (arrow head) in medulla at day 11 . 

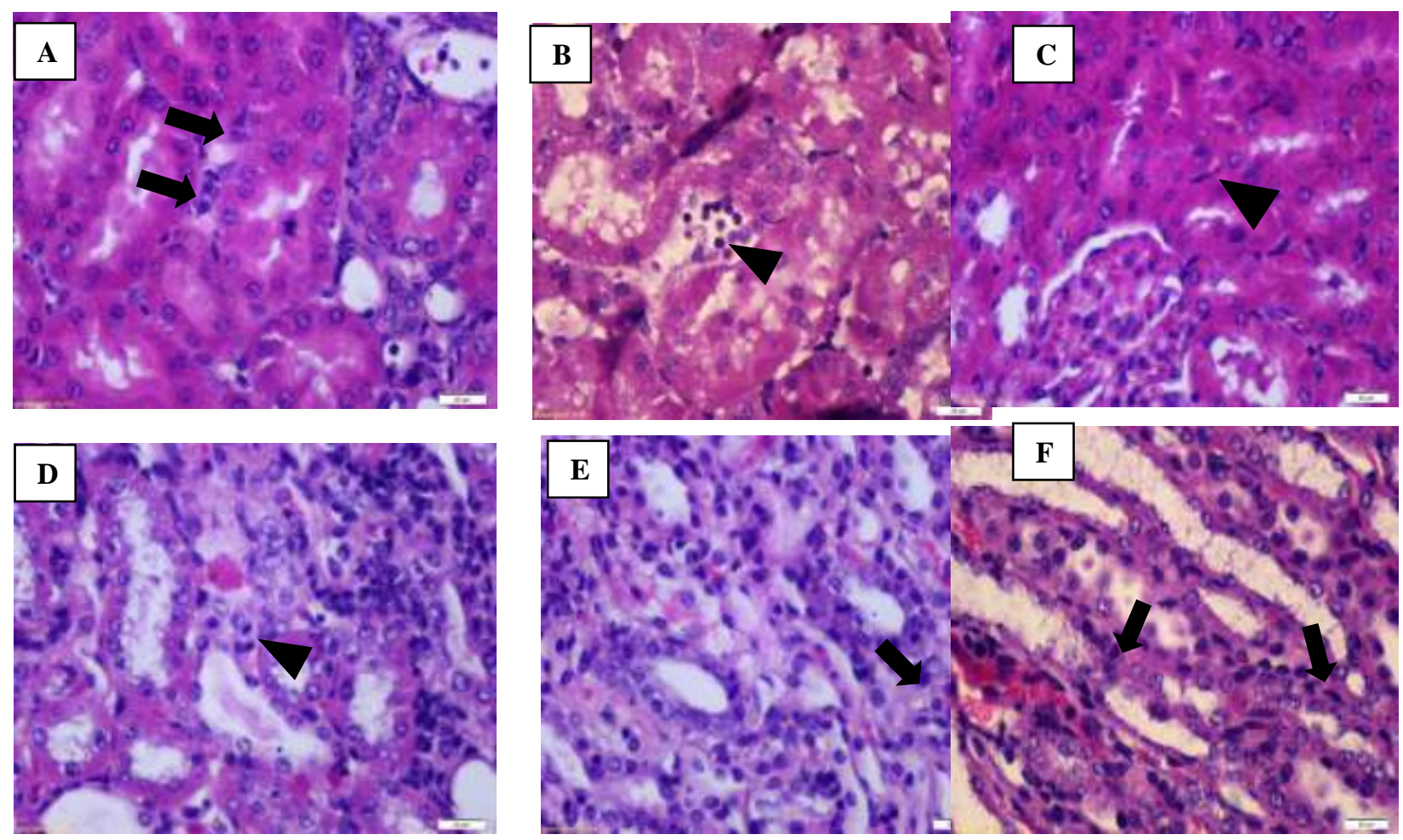

Fig. (11): Renal regenerative changes in retinoic acid group.

A) Mitotic figures (Black arrow) in cortex at day 3 .

B) Mild prominent nucleoli (Black arrowhead) in cortex at day 7 .

C) Marked prominent nucleoli (Black arrowhead) in cortex at day 11 .

D) Marked prominent nucleoli (Black arrowhead) in the medulla at day 3 .

E) Mitotic figures (Black arrow) in medulla at day 7.

F) Mitotic figure (Black arrow) in medulla at day 11.

\section{DISCUSSION:}

Cisplatin is a chemotherapy that is a commonly used antineoplastic agent; it is globally used for the treatment of many solid-organ tumors. Despite of its massive use, higher doses or small doses with long periods induce renal toxicity [22]. The most common form of renal toxicity related to cisplatin intake is the nephrotoxicity, especially, acute tubular necrosis, which limits the use of the drug [23].

In the literature several experimental models have been conducted on AKI, some of them were used ischemia/reperfusion models to induce AKI [24], others used drugs such as cisplatin or folic acid of Mercuric chloride $\left(\mathrm{HgCl}_{2}\right)$ [25]. In the present study, a single dose of Cisplatin (6 mg/kg b.w, i.p) was used for AKI induction, it was found that Cisplatin significantly increased serum creatinine, BUN and Microalbuminuria compared to control group, which indicated the development of AKI. The present results 
are in agreement with other studies [26]. Administration of ATRA one day after cisplatin injection was found to ameliorate renal functions that appeared in the significant reduction in serum creatinine, BUN and Microalbuminuria levels compared to cisplatin group, the present results are in the line with Cem et al., 2019 [27], who demonstrated that administration of (ATRA + Cisplatin) lead to a significant reduction in urea and creatinine levels, so ATRA has positive effects in amelioration of renal functions.

Cisplatin is not an oxidant agent, but it has the ability to generate reactive oxygen species (ROS) which are the main causes for induction of cisplatin nephrotoxicity [28], cisplatin can produce reactive oxygen species by disrupting the respiratory chain and cause mitochondrial dysfunction, at the same time, reactive oxygen species reduce the antioxidant enzyme activity and intracellular concentrations of antioxidants by reacting with thiol-containing molecules such as glutathione [29]. In this study, injection of cisplatin caused a significant increase in MDA contents (an oxidant agent), and a marked decrease in GSH and CAT activities (antioxidant agents). The results are also in agreement with previous studies reported that injection of cisplatin is accompanied with a significant elevation of MDA content and a marked depletion in GSH content as well as SOD and CAT activities [30]. ATRA is known to have free radical scavenger effects [31], which explain the present results that found that administration of ATRA attenuated the effects of ROS through the decreasing of MDA content and increasing of GSH and CAT activities.

Cisplatin was reported to increase the apoptosis and as a result induces the inflammation and fibrogenesis [32], another study confirmed that, beside the generation of oxidative stress, cisplatin can also induce renal histomorphological damage, apoptosis and inflammation [33]. In agreement with the previous data, injection of Cisplatin in the present study resulted in the induction of renal tubular cells apoptosis, which indicated through leading to significant elevation in the levels of apoptotic marker caspase-3 in cisplatin group especially on day 3 when compared with control group, these results are also in the line with (Iwayama and Ueda, 2013) [34], who reported that the injection of cisplatin principally lead to induction of renal tubular cells apoptosis. On the other hand administration of ATRA markedly reduced caspase 3 expression when compared with cisplatin group at 3,7 and 11 days, which reflect the protective effect of ATRA against apoptosis. In support of this result, kitamura et al., [35], documented that RA inhibits apoptosis induced by hydrogen peroxide in mesangial cells.

Cisplatin injection is also associated with renal inflammation and fibrogenesis as mentioned above, NF-kB has an expressing role for pro-inflammatory genes such as cytokines, chemokines, and adhesion molecules, so it can be expressed as a potential target for testing any anti-inflammatory agent [36], the elevated level of $\mathrm{NF}_{\mathrm{kB}}$ after cisplatin injection can be explained by the fact that, cisplatin induce the phosphorylation of $\mathrm{NF}_{\mathrm{kB}}$ and degrading the inhibitory protein $\mathrm{IkB}_{\alpha}$ and subsequently, it facilitates the translocation of $\mathrm{NF}_{\mathrm{kB}}$ to the nucleus, and hence increasing its gene expression level [37], in the present study, injection of cisplatin increased $\mathrm{NF}_{\mathrm{kB}}$ mRNA gene expression in cisplatin group compared with control group, which was in agreement with previous study performed by Bayomi, et al., (2013) [38]. By contrast, in ATRA treated group, the present results revealed that, ATRA markedly reduced $\mathrm{NF}_{\mathrm{kB}} \mathrm{mRNA}$ gene expression compared with cisplatin group, Consistent with these findings, Rao et al., 2013, documented that ATRA was able to ameliorate liver injury in a liver I/R model by inhibiting NF-kB activation by suppressing the phosphorylation of $\mathrm{NF}_{\mathrm{kB}}$, suppressing the degradation of $\mathrm{IkBa}$ protein, decreasing neutrophil recruitment and activity and decreasing inflammatory cytokine levels [39].

It was reported that ATRA has an anti-inflammatory effect, which was appeared in anti-glomerular basement membrane glomerulonephritis in rats and in a mouse model of lupus nephritis [40]. One of the most important fibrogenic cytokine agents that induce the release of inflammatory cells and fibroblasts into the injured site is the Transforming growth factor- $\beta 1$ TGF- $\beta 1$ [41]. These results revealed that cisplatin injection resulted in the elevation of TGF $\beta 1$ expression level and that was in agreement with Elseweidy et al. (2018) [42], administration of ATRA reduced the expression level of TGF $\beta 1$ in ATRA treated group and 
that was compatible with Yi li et al. (2013) who found that ATRA treatment can reduce the expression of TGF- $\beta 1$ in UUO rats [43].

The present study found that severe Histopathological damage followed after cisplatin injection which was marked on day 3 , and appeared as interstitial inflammatory infiltrate, tubular dilation, and loss of brush borders and necrosis, that was in agreement with Atasayar et al., (2009), who demonstrated that cisplatin administration induces characteristic Histopathological features in kidney structure [44]. Cisplatininduced Histopathological damage was attributed to oxidative molecules resulted from cisplatin injection and the inflammatory response that developed against these molecules [45]. In the present study, ATRA administration along with cisplatin was noted to reduce kidney damage and led to mild tubular degeneration and mild necrosis, and this study considered that the recovery of the Histopathological damage in ATRApretreated group results from the anti-inflammatory and antioxidant effects of ATRA.

\section{CONCLUSION:}

The present study showed that ATRA has a renoprotective effect on AKI, that can be mediated through their antioxidant and anti-inflammatory effects.

\section{CONFLICT OF INTEREST:}

The authors disclose any conflict of interest.

\section{REFERENCES:}

[1] BELlOMO, R., KELlUM, JA., AND RONCO, C. Acute kidney injury. The Lancet., 380 (9843), p.756-766, 2012.

[2] THIELE, RH., ISBELL, JM., \& ROSNER, MH. AKI associated with cardiac surgery. Clin. J. Am. Soc. Nephrol., 10, 500-514, 2015.

[3] KODAMA, A., WATANABE, H., TANAKA, R., KONDO, M., GIAM CHUANG, VT., WU, Q., ENDO, M., ISHIMA, Y., FUKAGAWA, M., OTAGIRI, M., AND MARUYAMA, T. "Albumin fusion renders thioredoxin an effective anti-oxidative and anti-inflammatory agent for preventing cisplatin-induced nephrotoxicity," Biochimica et Biophysica Acta., vol. 1840, pp. 1152-1162, 2014.

[4] SERPELONI, JM., BATISTA, BL., ANGELI, JP., BARCELOS, GR., BIANCHI, M DE L., BARBOSA, JR F., AND ANTUNES, LM. Antigenotoxic properties of chlorophyll b against cisplatin-induced DNA damage and its relationship with distribution of platinum and magnesium in vivo. J Toxicol Environ Health A., 76:345-353, 2013.

[5] HAVASI, A., AND BORKAN, SC. Apoptosis and acute kidney injury. Kidney Int., 80: 29-40, 2011.

[6] JIANG, M., WEI, Q., WANG, J., ET AL. Regulation of PUMA-alpha by p53 in cisplatin-induced renal cell apoptosis. Oncogene., 25: 4056-4066, 2006.

[7] SIDDIK, ZH. "Cisplatin: mode of cytotoxic action and molecular basis of resistance," Oncogene., vol. 22, no. 47, pp. 7265-7279. 2003.

[8] AYDINOZ, S., UZUN, G., CERMIK, H., ET AL. "Effects of different doses of hyperbaric oxygen on cisplatin-induced nephrotoxicity," Renal Failure., vol. 29, no. 3, pp. 257-263, 2007.

[9] TANABE, K., TAMURA, Y., LANASPA, MA., MIYAZAKI, M., SUZUKI, N., SATO, W., MAESHIMA, Y., SCHREINER, GF., VILLARREAL, FJ., JOHNSON, RJ., NAKAGAWA, T. Epicatechin limits renal injury by mitochondrial protection in cisplatin nephropathy. Am J Physiol Renal Physiol., 303 (9):F1264-1274, 2012. 
[10] POURJAFAR, M., ET AL. All-trans retinoic acid preconditioning enhances proliferation, angiogenesis and migration of mesenchymal stem cell in vitro and enhances wound repair in vivo. Cell proliferation., 50 (1): p. e12315, 2017.

[11] HUMES, HD., AND CIESLINSKI, DA. Interaction between growth factors and retinoic acid in the induction of kidney tubulogenesis in tissue culture. Exp Cell Res., 201: 8-15, 1992.

[12] OSETO, S., MORIYAMA, T., KAWADA, N., NAGATOYA, K., TAKEJI, M., ANDO, A., YAMAMOTO, T., IMAI, E., HORI, M. Therapeutic effect of all trans retinoic acid on rats with anti-GBM antibody glomerulonephritis. Kidney Int., 64(4):1241-1252, 2003.

[13] CAMBIASO, COLLET-CASSART, AND LIEVENS, M. Immunoassay of low concentrations of albumin in urine by latex particle counting. Clinical chemistry, 34 (2): p. 416-418, 1988.

[14] CLAIBORNE, A., Catalase, Activity. In: Robert AG (ed) CRC handbook of methods for oxygen radical research. CRC Press in Boca Raton, Fla. pp. 283-284, 1985.

[15] BEUTLER, E., DURON, O., KELLY, BM. Improved method for the determination of blood glutathione. J Lab Clin Med, 61:882-888, 1963.

[16] BUEGE, JA., AUST, SD., Microsomal lipid peroxidation. Methods Enzymol., 52: 302-310, 1978.

[17] JIANG, W., YU, Q., GONG, M., CHEN, L., WEN, EY., BI Y, ET AL. Vitamin A deficiency impairs postnatal cognitive function via inhibition of neuronal calcium excitability in hippocampus. Journal of Neurochemistry., 121 (6):932-43, 2012.

[18] GHASEMZADEH-HASANKOLAEI, M., ESLAMINEJAD, MB AND BATAVANI, R. Male and female rat bone marrow derived mesenchymal stem cells are different in terms of the expression of germ cell specific genes. Anat Sci Int., 90 (3): 187-196. 2015.

[19] IMAM, F., AL-HARBI, NO., AL-HARBI, MM., ANSARI, MA., ZOHEIR, KM., IQBAL, M., ANWER,CK., AL HOSHANIA, AR., ATTIAA, SM., AND AHMAD S. Diosmin downregulates the expression of $\mathrm{T}$ cell receptors, pro-inflammatory cytokines and NF- $\mathrm{kB}$ activation against LPSinduced acute lung injury in mice. Pharmacological research, 102, 1-11. 2015.

[20] ZHENG, L., HUIMIN, L., XIAOMENG, S., RONG, G., RUIBING, C., XIANGXING, M., AND MING,Y. RNA Interference against Discoidin Domain Receptor 2 Ameliorates Alcoholic Liver Disease in Rats. PLoS One, 8(2): e55860, 2013.

[21] SHOKEIR, AA., HUSSEIN, AM., BARAKAT, N., ABDElAZIZ, A., ELGARBA, M., AND AWADALLA, A. Activation of nuclear factor erythroid 2-related factor 2 (Nrf2) and Nrf-2dependent genes by ischaemic pre-conditioning and post-conditioning: new adaptive endogenous protective responses against renal ischaemia/ reperfusion injury. Acta Physiol, 210, 342-353. 2014.

[22] TAGUCHI, T., NAZNEEN, A., ABID, MR., RAZZAQUE, MS. Cisplatin associated nephrotoxicity and pathological events. Contrib Nephrol., 148:107-121, 2005.

[23] KIM, CS., PARK, JS., AHN, CW., KIM, KR. All-trans retinoic acid has a potential therapeutic role for diabetic nephropathy. Yonsei Med J., 56 (6):1597-1603, 2015.

[24] LI B., COHEN, A., HUDSON, TE. Mobilized human hematopoietic stem/progenitor cells promote kidney repair after ischemia/reperfusion injury. Circulation., 121:2211-2220, 2010.

[25] FANG, TC., ALISON, MR., COOK, HT. Proliferation of bone marrow-derived cells contributes to regeneration after folic acid-induced acute tubular injury. J Am Soc Nephrol.,16:1723-1732, 2005.

[26] SINDHU, G., NISHANTHI, E., SHARMILA, R. Nephroprotective effect of vanillic acid against cisplatin induced nephrotoxicity in wistar rats: a biochemical and molecular study. Environ Toxicol Pharmacol., 39: 392-404, 2015.

[27] CEM, YUCEL., ELCIN ERDOGAN YUCEL, FATMA DEMET ARSLAN, ET AL. All-trans retinoic acid prevents cisplatin-induced nephrotoxicity in rats. Naunyn-Schmiedeberg's Arch Pharmacol. part of Springer Nature, 2019.

[28] PABLA, N., DONG, Z. Cisplatin nephrotoxicity: mechanisms and renoprotective strategies. Kidney Int., 73:994-1007, 2008. 
[29] OZKOK, A., AND EDELSTEIN, CL. Pathophysiology of cisplatin-induced acute kidney injury, BioMed research international., 2014.

[30] PAN, H., MUKHOPADHYAY, P., RAJESH, M., PATEL, V., MUKHOPADHYAY, B., GAO, B., HASKÓ, G., PACHER, P. Cannabidiol attenuates cisplatin-induced nephrotoxicity by decreasing oxidative/nitrosative stress, inflammation, and cell death. J Pharmacol Exp Ther., 328:708-714, 2009.

[31] SHI, H., ET AL. The mechanism of all-trans retinoic acid in the regulation of apelin expression in vascular endothelial cells. Bioscience reports., 37 (6). 2017.

[32] OSETO, S., MORIYAMA, T., KAWADA, N., NAGATOYA, K., TAKEJI, M., ANDO, A., YAMAMOTO, T., IMAI, E., HORI, M. Therapeutic effect of all-trans retinoic acid on rats with anti-GBM antibody glomerulonephritis. Kidney Int., 64 (4):1241-1252, 2003.

[33] BARADARAN, A., ET AL. Cisplatin; nephrotoxicity and beyond, Annals of Research in Antioxidants. 1(2), 2016.

[34] IWAYAMA, H., AND UEDA, N. Role of mitochondrial Bax, caspases, and MAPKs for ceramideinduced apoptosis in renal proximal tubular cells. Molecular and cellular biochemistry, 379 (1-2): p. 37-42. 2013.

[35] KITAMURA, M., ISHIKAWA, Y., MORENO-MANZANO, V. ET AL. Intervention by retinoic acid in oxidative stress-induced apoptosis. Nephrol Dial Transplant, 17 [Suppl 9]: 84-87, 2002.

[36] RAJU, N. ET AL. Cuscuta chinensis ameliorates immunosuppression and urotoxic effect of cyclophosphamide by regulating cytokines-GM-CSF and TNF-alpha, applied biochemistry and biotechnology, 176 (3): p. 742-757, 2015.

[37] SUNG, MJ, ET AL. Genistein protects the kidney from cisplatin-induced injury. Kidney international, 74 (12): p. 1538-1547, 2008.

[38] BAYOMI, HS, ET AL. Evaluation of renal protective effects of inhibiting TGF- $\beta$ type I receptor in a cisplatin-induced nephrotoxicity model. European cytokine network., 24 (4): p. 139-147, 2013.

[39] RAO, J., QIAN, X., WANG, P., PU, L., ZHAI, Y., WANG, X., ZHANG, F., AND LU, L. All-trans retinoic acid preconditioning protects against liver ischemia/reperfusion injury by inhibiting the nuclear factor kappa B signaling pathway. J. of Surg. Res., 180: 99 - 106, 2013.

[40] LAZZERI, ET AL. Retinoids and glomerular regeneration in Seminars in nephrology. Elsevier, 2014.

[41] ELSHERBINY, NM., ELADL, MA., AND AL-GAYYAR, MM. Renal protective effects of arjunolic acid in a cisplatin-induced nephrotoxicity model. Cytokine, 77: p. 26-34, 2016.

[42] ELSEWEIDY, MM., ET AL. Nephrotoxicity induced by cisplatin intake in experimental rats and therapeutic approach of using mesenchymal stem cells and spironolactone, Applied biochemistry and biotechnology., 184 (4): p. 1390-1403, 2018.

[43] LI, ZY., ET AL. All-Trans Retinoic Acid Attenuates the Renal Interstitial Fibrosis Lesion in Rats but Not By Transforming Growth Factor- $\beta$ 1/Smad3 Signaling Pathway, Renal failure., 35 (2): p. 262-267, 2013.

[44] ATASAYAR, S., GÜRER-ORHAN, H., ORHAN, H., GÜREL, B., GIRGIN, G., AND OZGÜNEŞ, H. Preventive effect of aminoguanidine compared to vitamin $\mathrm{E}$ and $\mathrm{C}$ on cisplatin-induced nephrotoxicity in rats. Exp Toxicol Pathol, 61:23-32, 2009.

[45] ALIBAKHSHI, T., KHODAYAR, MJ, KHORSANDI, L., RASHNOM, ZEIDOONI, L. Protective effects of zingerone on oxidative stress and inflammation in cisplatin-induced rat nephrotoxicity. Biomed Pharmacother, 105: 225-232, 2018. 